\title{
ULAM'S TYPE STABILITY OF A FUNCTIONAL EQUATION DERIVING FROM QUADRATIC AND ADDITIVE FUNCTIONS
}

\section{ABASAlt BodAghi AND SANG OG KIM}

Abstract. In this paper, we continue the investigation of functional equation which is begun by the authors in the first part. We also prove the Hyers-Ulam stability for the following mixed quadratic-additive functional equation in quasi-Banach spaces.

$$
\begin{aligned}
f(x+m y)+f(x-m y) & \\
& = \begin{cases}2 f(x)-2 m^{2} f(y)+m^{2} f(2 y) & m \text { is even } \\
f(x+y)+f(x-y)-2\left(m^{2}-1\right) f(y)+\left(m^{2}-1\right) f(2 y), & m \text { is odd. }\end{cases}
\end{aligned}
$$

Mathematics subject classification (2010): Primary 39B82, 46S50, 46S40.

Keywords and phrases: Additive mapping, Hyers-Ulam stability, quadratic mapping, quasi-Banach space.

\section{REFERENCES}

[1] T. AOKI, On the stability of the linear transformation in Banach spaces, J. Math. Soc. Japan 2 (1950), 64-66.

[2] Y. Benyamini And J. Lindenstrauss, Geometric nonlinear functional analysis, Vol.1, American Mathematical Society Colloquium Publications, 48. American Mathematical Society, Providence, RI, 2000.

[3] A. Bodaghi And I. A. Alias, Approximate ternary quadratic derivations on ternary Banach algebras and $C^{*}$-ternary rings, Advances in Difference Equations, 2012, Article No. 11, 9 pages (2012).

[4] A. Bodaghi, I. A. Alias And M. H. Ghahramani, Ulam stability of a quartic functional equation, Abs. Appl. Anal. 2012, Art. ID 232630 (2012).

[5] A. BodAghi, S. Y. JANG AND C. PARK, On the stability of Jordan *-derivation pairs, Results. Math. 64 (2013), 289-303.

[6] A. Bodaghi AND S. O. KIM, Stability of a functional equation deriving from quadratic and additive functions in non-Archimedean normed spaces, Abs. Appl. Anal. 2013, Art. ID 198018 (2013).

[7] D. G. Bourgin, Classes of transformations and bordering transformations, Bull. Amer. Math. Soc. 57 (1951), 223-237.

[8] N. BRILlouËT-BELluOT, J. BRZDȨK AND K. CIEPLIŃS KI, On some recent developments in Ulam's type stability, Abstract and Applied Analysis, vol. 2012, Article ID 716936, 41 pages, 2012.

[9] J. BRZDȨK, Stability of the equation of the p-Wright affine functions, Aequationes Mathematicae 85 (2013), 497-503.

[10] L. CĂDARIU AND V. RADU, Fixed points and the stability of quadratic functional equations, An. Univ. Timişoara, Ser. Mat. Inform. 41 (2003), 25-48.

[11] P. W. Cholewa, Remarks on the stability of functional equations, Aequationes Math. 27 (1984), $76-86$.

[12] K. Ciepliński, Applications of fixed point theorems to the Hyers-Ulam stability of functional equations-a survey, Annals of Functional Analysis 3, 1 (2012), 151-164.

[13] G. Z. Eskandani, H.VAezi And Y. N. Dehghan, Stability of a mixed additive and quadratic functional equation in non-Archimedean Banach modules, Taiwanese J. Math. 14, 4 (2010), 13091324. 
[14] P. GĂVRUTA, A generalization of the Hyers-Ulam-Rassias stability of approximately additive mappings, J. Math. Anal. Appl. 184, 3 (1994), 431-436.

[15] D. H. HYERS, On the stability of the linear functional equation, Proc. Nat. Acad. Sci. USA. 27 (1941), 222-224.

[16] S. S. Jin AND Y. H. LEE, On the stability of the functional equation deriving from quadratic and additive function in random normed spaces via fixed point method, J. Chung. Math. Soc. 25, 1 (2012), $51-63$.

[17] A. Najati And M. B. Moghimi, Stability of a functional equation deriving from quadratic and additive functions in quasi-Banach spaces, J. Math. Anal. Appl. 337 (2008), 399-415.

[18] TH. M. Rassias, On the stability of the linear mapping in Banach spaces, Proc. Amer. Math. Soc. 72 (1978), 297-300.

[19] S. RolewICZ, Metric linear spaces, Second edition, PWN-Polish Scientific Publishers, Warsaw; D. Reidel Publishing Co., Dordrecht, 1984.

[20] F. SkоF, Proprietè locali e approssimazione di operatori, Rend. Sem. Mat. Fis. Milano 53 (1983), $113-129$.

[21] J. TABOR, Stability of the Cauchy functional equation in quasi-Banach spaces, Ann. Polon. Math. 83 (2004), 243-255.

[22] S. M. Ulam, Problems in Modern Mathematics, Chapter VI, Science Ed., Wiley, New York, 1940. 